\title{
Cause of Death Certification in COVID-19 Deaths
}

\author{
Chandrakanth Hungund Veeranna ${ }^{1}$, Smitha Rani ${ }^{2}$
}

\begin{abstract}
Introduction: Appropriate cause of death reporting is vital in the pandemic circumstance for effective planning of the control measures. Accurate reporting and registration of the reason for death are crucial in planning of health programs in turn contributing for the national development. Background: All births and deaths occurring across India should be mandatorily registered per the Registration of Births and Deaths Act passed in the year 1969. The act also requires the issuance of cause of death certificate by the doctor attending the departed during his last illness. Data obtained from the cause of death certificate provides cause-specific mortality profile, which is required to analyze the health trends of the population.

Review results: This article discusses the available guidelines on the appropriate documentation of cause of death in the confirmed or suspected coronavirus disease-2019 (COVID-19) infection resulting into death.

Conclusion: Proper certification of the cause of death leads to better epidemic surveillance. Scrutiny of the clinical sequences from the cause of death certificate is useful to prioritize the allocation of resources for critical care management and to augment our knowledge about underlying causes resulting in mortality from COVID-19.

Clinical significance: Dissemination of available guidelines on proper documentation of the cause of death in confirmed/suspected COVID-19 cases will reduce the errors in cause of death reporting.

Keywords: Cause of death, COVID-19, Medical certification of cause of death, Mortality statistics.

Indian Journal of Critical Care Medicine (2020): 10.5005/jp-journals-10071-23561
\end{abstract}

\section{BACKGROUND}

The civil registration system in India aids in recording of births and deaths under a legislative policy, dating back to the British era. Central Births, Deaths and Marriages Registration Act was passed in the year 1886 which offered voluntary registration. The Registration of Births and Deaths (RBD) Act enforced in 1969 overcame the then prevalent varied provisions of law pertaining to births and deaths registration in India. It integrated the system of registration across the country making the registration process mandatory. ${ }^{1}$ As per the RBD Act, information on the births and deaths occurring in a health facility and such other like institutions should be provided by the doctor in charge or a person authorized on his behalf. ${ }^{2}$

The act also requires that the medical practitioner has to issue a cause of death certificate if the deceased is attended by him during his terminal illness. The certificate should be issued without charging any fee. The certificate issued should be in the prescribed format, i.e., form no. 4 for institutional deaths and form 4 A for noninstitutional deaths. The certificate should be sent to the registrar along with form no. 2 which is a death reporting form. ${ }^{3}$

The medical certification of cause of death (MCCD) scheme falls under the legal ambit of RBD Act and is implemented in all the medical institutions in the country, including government, private, and non-profit-making healthcare facilities. ${ }^{4}$

Data obtained from MCCD provides cause-specific mortality profile, which is required to analyze the health trends of the population. Precise reporting of causes of death has a key role in planning of health programs and national development. Appropriate cause of death reporting is exceptionally relevant in the situation of a pandemic for effective planning of the control measures.
1,2Department of Forensic Medicine and Toxicology, JSS Medical College, JSS Academy of Higher Education and Research, Mysuru, Karnataka, India

Corresponding Author: Smitha Rani, Department of Forensic Medicine and Toxicology, JSS Medical College, JSS Academy of Higher Education and Research, Mysuru, Karnataka, India, Phone: +91 9886673946, e-mail: smitha_2444@yahoo.co.in

How to cite this article: Veeranna $\mathrm{CH}$, Rani S. Cause of Death Certification in COVID-19 Deaths. Indian J Crit Care Med 2020;24(9): 863-867.

Source of support: Nil

Conflict of interest: None

\section{Review Results}

Wuhan Municipal Health Commission, China, at Wuhan, Hubei province, first reported corona virus disease (COVID-19) in late 2019. The World Health Organization (WHO) declared the disease outbreak as a public health emergency of international concern on January 30, 2020. The disease was declared as a global pandemic on March 11, 2020. ${ }^{5}$

During such circumstances, mortality surveillance is a vital public health tool to evaluate the impact of the disease. Correct death certification is necessary to recognize the disease burden and its progression. Death certificate data can inform the public and policymakers on the progress of the COVID-19 pandemic and provide valuable information about who is dying, where they are from, and what were their associated medical conditions. ${ }^{6}$

(-) The Author(s). 2020 Open Access This article is distributed under the terms of the Creative Commons Attribution 4.0 International License (https://creativecommons. org/licenses/by-nc/4.0/), which permits unrestricted use, distribution, and non-commercial reproduction in any medium, provided you give appropriate credit to the original author(s) and the source, provide a link to the Creative Commons license, and indicate if changes were made. The Creative Commons Public Domain Dedication waiver (http://creativecommons.org/publicdomain/zero/1.0/) applies to the data made available in this article, unless otherwise stated. 
When COVID-19 is determined to be the cause for death, it must be stated on the death certificate to measure the effects of the pandemic accurately and aptly undertake public health response. Monitoring the emergence of COVID-19 and guiding public health response requires precise and timely reporting of death. ${ }^{7}$ Hence, the objective of this article is to discuss the available guidelines on the appropriate cause of death certification in confirmed or suspected COVID-19 infection leading to death. These guidelines are based on the guidance notified by Department of Health Research, Ministry of Health and Family Welfare, Govt. of India, ${ }^{8}$ which is in concurrence with international guidelines for certification and classification (coding) of COVID-19 as cause of death formulated by WHO. ${ }^{9}$

\section{Medical Certification of Cause of Death Format}

International statistical classification of diseases and related health problems (ICD) manual published by WHO contains a format for cause of death certification. It necessitates the certifying doctors to document the pathophysiological sequence of clinical conditions leading to death, their time interval, and other contributory causes. $^{10}$

The format of the certificate prescribed in India (Annexure 1) conforms to the standard recommended by the WHO. Cause of death fragment in the certificate is divided into:

- Part I: It comprises the immediate cause of death which is entered in line (a) and antecedent causes needs to be filled in line (b) and (c)

- Part II: Other significant conditions contributing to death but not related to the diseases or conditions causing it are entered in part II.

Death often is an outcome of combined effect of two or more independent or related conditions. One condition may lead to another, which in turn can lead to a third condition. Wherever there is a sequence, the underlying cause of death is coded with ICD-10 codes and is considered for statistical purposes. The disease or injury that starts the train of morbid events and leads directly to death or the situations of the accident or violence which produces the fatal injury is labeled as underlying cause of death. The morbid conditions or injuries resulting from the underlying cause of death are called as antecedent and immediate cause. ${ }^{11}$

Information under part I pertains to the underlying cause of death, antecedent cause of death, and immediate cause of death, written from below upward, clearly portraying the sequence of events ending with immediate cause written in line (a). The sequence gives the order of association between the events leading to death both with respect to time, etiological or pathological relationship. Properly recording the sequence helps to adopt suitable strategies to cut the chain of events at its most susceptible point and thus prevent death. The original format, approved by WHO, had only (a), (b) and (c) under part I. As per the recommendations of Forty-Third World Health Assembly 1990, an extra line (d) has been added below (c). ${ }^{12}$

The form must be filled by the attending doctor having firsthand knowledge regarding the clinical history. Parenthetical statements and abbreviations should not be used while reporting the cause of death. Single cause must be documented on each line of part I. The underlying cause of death has to be entered on the last line used in the part I. Immediate cause of death stated on line (a) can be a sole entry made in cause of death section, if that is the only condition leading to death. The immediate cause refers to the terminal disease, injury, or complication directly producing the death. It does not refer to the mechanism of death or final event. Death mechanisms such as cardiac arrest or respiratory arrest must not be stated as the immediate cause of death, as it is a statement not clearly related to the disease process, and it just indicates to the fact of death. ${ }^{13}$

\section{Cause of Death Certification in Deaths from COVID-19 Definition of Death Resulting From COVID-19}

As per the guidelines issued by WHO, death due to COVID-19 is defined for surveillance purposes as, "a death resulting from a clinically compatible illness, in a probable or confirmed COVID-19 case, unless there is a clear alternative cause of death that cannot be related to COVID disease (e.g. trauma)".There must not be a period of complete recovery from COVID-19 amid illness and death. ${ }^{9}$

\section{Terminologies to be Used While Certifying the Cause of Death ${ }^{9}$}

Since there are various types of coronaviruses, it is suggested that one should not use the term "coronavirus" instead of COVID-19. This aids in decreasing the ambiguity for the classification or coding and to screen these deaths correctly. Although COVID-19 (Corona virus disease-19) is an abbreviation, it is WHO specified and is acceptable term to be recorded as an underlying cause of death.

\section{Completing MCCD Resulting From COVID-198}

COVID-19 is a viral infection, which can present as 'influenza-like illness' (ILI) or "Severe acute respiratory illness" (SARI). They are nonspecific to the disease itself, and hence they can be used in the sequence of the events but not an underlying cause of death.

COVID-19 is said to cause pneumonia/acute respiratory distress syndrome (ARDS)/cardiac injury/disseminated intravascular coagulation etc. which may result into death and maybe entered in line (a) or (b). COVID-19 is likely the underlying cause of death that results into ARDS or pneumonia in most of the cases of COVID-19 deaths (test positive and symptoms positive). In such scenarios, COVID-19 must be entered in the last line/lowest line of part I of MCCD form 4/4 A. Since acute respiratory failure is a mode of death, it should not be written in line $\mathrm{a} / \mathrm{b} / \mathrm{c}$.

Patients may have other preexisting comorbid conditions, such as chronic obstructive pulmonary disease, asthma, chronic bronchitis, ischemic heart disease, cancer, and diabetes mellitus. These conditions increase the risk of developing respiratory infections and may lead to complications and severe disease in a COVID-19 positive individual. These conditions are not considered as the underlying cause of death, as they have directly not caused death due to COVID-19. A patient may have many comorbid conditions, but only those which contributed to death must be recorded in part II.

\section{COVID-19 Case Definitions for Global Surveillance as Prescribed by $W H O^{9}$}

Confirmed case: "A confirmed case is a person with laboratory confirmation of infection with the COVID-19 virus, irrespective of clinical signs and symptoms."

Suspected case: "A patient with acute respiratory illness (that is, fever and at least one sign or symptom of respiratory disease, for example, cough or shortness of breath) with no other etiology that fully explains the clinical presentation and a history of travel to or residence in a country, area, or territory that has reported 
local transmission of COVID-19 disease during the 14 days prior to symptom onset."

OR

- "A patient with any acute respiratory illness and who has been a contact of a confirmed or probable case of COVID-19 disease during the 14 days prior to the onset of symptoms."

OR

- "A patient with severe acute respiratory infection (i.e., fever and at least one sign or symptom of respiratory disease, for example, cough or shortness breath) and who requires hospitalization and who has no other etiology that fully explains the clinical presentation."

Probable case: "A probable case is a suspected case for whom the report from laboratory testing for the COVID-19 virus is inconclusive."

\section{Discussion}

\section{Examples of Certification}

Example 1: A 40-year-old male was tested positive for COVID-19 two weeks back. He developed pneumonia 1 week later and suffered from respiratory distress for the last 3 days before his death.

For the abovementioned case scenario, the chain of events to be recorded in MCCD is given in Table 1.

Example 2: A 70-year-old female, who was a primary contact of a patient tested positive for COVID-19, presented with influenza-like illness of 4 days duration. She developed respiratory distress and died a day later. The test result of COVID-19 is not available. She has been suffering from type 2 diabetes mellitus for the past 10 years.

In the above case, conditions leading to death has to be mentioned in part I, and comorbidities to be reported in part II (Table 2).

Individuals with COVID-19 may die due to other diseases or accidents, such cases are not deaths resulting from COVID-19,

Table 1: Certification of cause of death for example 1

\begin{tabular}{lll}
\hline & Cause of death & $\begin{array}{l}\text { The interval between } \\
\text { onset and death approx. }\end{array}$ \\
\hline Part I & & \\
Immediate cause & $\begin{array}{l}\text { (a) Acute respiratory } \\
\text { distress syndrome }\end{array}$ & 3 days \\
Antecedent cause & $\begin{array}{l}\text { (b) Pneumonia } \\
\text { (c) COVID-19 (test } \\
\text { positive) }\end{array}$ & 7 days \\
& & \\
Part II & & \\
\hline
\end{tabular}

Table 2: Certification of cause of death for example 2

\begin{tabular}{|c|c|c|}
\hline & Cause of death & $\begin{array}{l}\text { Interval between onset } \\
\text { and death approx. }\end{array}$ \\
\hline \multicolumn{3}{|l|}{ Part I } \\
\hline Immediate cause & $\begin{array}{l}\text { (a) Acute respiratory } \\
\text { distress syndrome }\end{array}$ & 1 day \\
\hline \multirow[t]{2}{*}{ Antecedent cause } & $\begin{array}{l}\text { (b) Influenza like } \\
\text { Illness }\end{array}$ & 4 days \\
\hline & $\begin{array}{l}\text { (c) Suspected } \\
\text { COVID-19 }\end{array}$ & 4 days \\
\hline Part II & Diabetes mellitus & 10 years \\
\hline
\end{tabular}

and they should not be certified as such. In such circumstances, if the certifier is convinced that the COVID-19 intensified the consequences of the accident, COVID-19 can be reported in part II as a contributory cause.

Manner of death in COVID-19 infection is frequently "natural," as it is the disease that causes death. If an individual tested positive for COVID-19 commits suicide, the manner of death must be recorded as suicide / pending investigation if the medical autopsy is awaited. ${ }^{8}$

Most of the deaths from COVID-19 occur in a hospital setup, and in such cases, the place of death should be recorded as "Hospital." Cases where death of the individuals occurs in their residence after being discharged from the hospital, the place of death must be noted as "House." ${ }^{8}$

\section{ICD-10 Coding of COVID-19}

International classification of diseases (ICD) is the global health information standard for mortality and morbidity statistics. It is the foundation for the identification of health trends and statistics globally. It organizes data into standard groupings of diseases, allowing easy storage, retrieval, and interpretation of health information for evidence-based policy making. It also aids in sharing the health information and comparing it with the trends in other hospitals, regions, settings, and countries. The ICD-10 uses alphanumeric code with a letter in the first position and a number in the second, third, and fourth positions; the fourth character follows a decimal point. The code numbers can range from A00.0 to Z99.9. Codes U00-U49 is kept reserved for the provisional assignment of new diseases of uncertain etiology. ${ }^{14}$

ICD codes assigned for COVID-19 are: ${ }^{15}$

U07.1: COVID-19, virus identified.

U07.2: COVID-19, virus not identified.

- Clinically-epidemiologically diagnosed COVID-19

- Probable COVID-19

- Suspected COVID-19

Although both categories, U07.1 (COVID-19, virus identified) and U07.2 (COVID-19, virus not identified), are appropriate for cause of death coding, it is recognized that in most of the countries details pertaining to laboratory confirmation of the disease will not be stated on the death certificate. In the absence of this point, it is suggested for mortality purposes only to code COVID19 provisionally to U07.1 unless it is specified as "probable" or "suspected."

A manual credibility check is endorsed for certificates reporting COVID-19, particularly for those certificates, where COVID-19 is reported but not designated as the single underlying cause of death. ${ }^{9}$

\section{Conclusion}

Strengthening cause of death certification is required in most of the countries across the globe for better epidemic surveillance. ${ }^{16}$ Since COVID-19 death certificates have considerable influence on local and national responses toward the evaluation and management of the pandemic, additional effort is required by the certifying doctor while reporting the cause of death.

\section{Clinical Significance}

Dissemination of available guidelines on proper documentation of the cause of death in confirmed/suspected COVID-19 cases will better equip the doctors to avoid errors in reporting. 


\section{References}

1. Civil Registration System Division. Office of the Registrar General \& Census Commissioner, India. Available from: https://censusindia.gov. in/vital_statistics/CRS/CRS_Division.html. (Accessed 16 June 2020).

2. The Registration of Births and Deaths Act, 1969 (18 of 1969). Delhi: Universal Law Publishing Co. Pvt. Ltd; 2006. pp. 6-8.

3. Physician's Manual on Medical Certification of Cause of Death. 5th ed., New Delhi: Vital Statistics Division, Office of the Registrar General, India, Ministry of Home Affairs; 2012.

4. Office of the Registrar General, Ministry of Home Affairs, Government of India. Extending the scheme of Medical Certification of Cause of Death (MCCD) to all medical institutions. Available from: https:// censusindia.gov.in/2011-Documents/mccd_Report1/Circular2.pdf. (Accessed 16 June 2020).

5. World Health Organization. WHOTimeline-COVID-19. Available from: https://www.who.int/news-room/detail/27-04-2020-who-timeline--covid-19 (Accessed 14 June 2020).

6. Gill JR, DeJoseph ME. The importance of proper death certification during the COVID-19 pandemic. JAMA, Online ahead of print 2020(1). DOI: 10.1001/jama.2020.9536.

7. National Center for Health Statistics. Guidance for certifying deaths due to COVID-19. Hyattsville, MD 2020.

8. National Centre for Disease Informatics and Research. Guidance for recording of COVID-19 related deaths in India. Available from: https://www.ncdirindia.org/Downloads/CoD_COVID-19_Guidance. pdf. (Accessed 19 June 2020).
9. World Health Organization. International guidelines for certification and classification (coding) of COVID-19 as cause of death. Available from: https://www.who.int/classifications/icd/Guidelines_Cause_of_ Death_COVID-19.pdf?ua=1. (Accessed 19 June 2020).

10. Mortality: guidelines for certification and rules for coding. International Statistical Classification of Diseases and Health Related Problems - Tenth Revision (ICD-10), vol. 2, Geneva: World Health Organization; 1993. Available from: https://www.who.int/ classifications/icd/ICD10Volume2_en_2010.pdf (Accessed 14 June 2020).

11. Office of the Registrar General of India, Vital Statistics Division: Physicians' Manual on Medical Certificate of Cause of Death. 4th ed., New Delhi: Ministry of Home Affairs, Govt of India; 2000.

12. Kotabagi RB, Chaturvedi RK, Banerjee A. Medical certification of cause of death. MJAFI 2004;60(3):261-272. DOI: 10.1016/S03771237(04)80060-1.

13. National Center for Health Statistics. Physicians' Handbook on Medical Certification of Cause of Death. Hyattsville, Maryland 2003.

14. World Health Organisation, International Classification of Diseases (ICD) Information Sheet. Available from: https://www.who.int/ classifications/icd/factsheet/en/. (Accessed 19 June 2020).

15. World Health Organisation, COVID-19 coding in ICD-10. Available from: https://www.who.int/classifications/icd/COVID-19-codingicd10.pdf?ua=1. (Accessed 19 June 2020).

16. Rao C. Elements of a strategic approach for Strengthening national mortality statistics programmes. BMJ Glob Health 2019;4(5):e001810. DOI: 10.1136/bmjgh-2019-001810. 


\section{Annexure 1}

FORM NO. 4

FORM NO. 4
(See Rule 7 )

MEDICAL CERTIFICATION OF CAUSE OF DEATH

(Hospital in-patients. Not to be used for still births)

To be sent to Registrar along with Form No.2 (Death Report)

Name of the Hospital

person whose particulars are given below died in the hospital in Ward No

I hereby certify that the .................P.M.

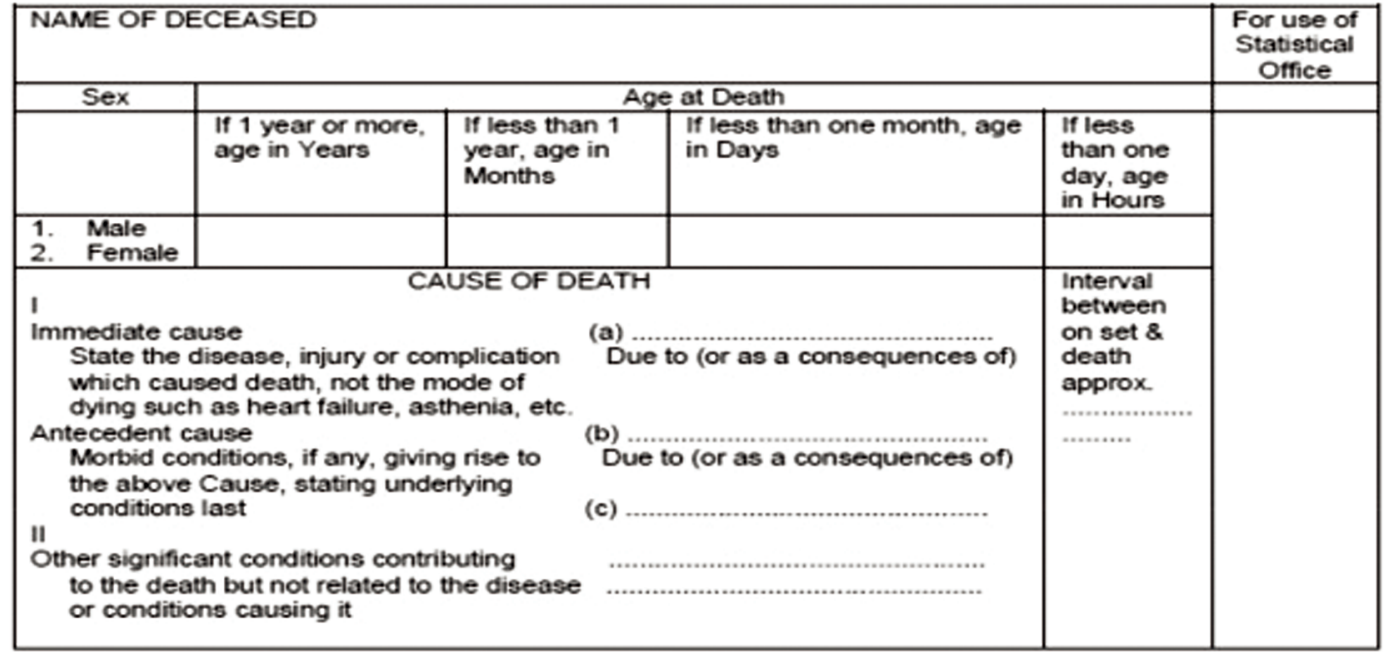

Manner of Death

How did the injury occur?

1. Natural 2. Accident 3. Suicide 4. Homicide

5. Pending investigation

If deceased was a female, was the death associated with pregnancy? 1. Yes 2. No

If yes, was there a delivery? 1. Yes 2. No

Name and signature of the Medical Attendant certifying the cause of death Date of certification

SEE REVERSE FOR INSTRUCTIONS

(To be detached and handed over to the relative of the deceased)

Certified that Shri/Smt/Kum. $\mathrm{R} / \mathrm{O}$ and expired on 